\title{
EFFECT OF WALL ASPECT RATIO ON SEISMIC RESPONSE OF NARROW MECHANICALLY STABILIZED EARTH WALLS
}

\author{
Ahmed S. Rabei ${ }^{1}$, Rami El-Sherbiny ${ }^{2}$, Omar Ezzeldine ${ }^{2}$ \& Mohamed I. Amer $^{2}$ \\ ${ }^{1}$ Cairo University and Teaching Assistant, Scientific Research Developing Unit, Beni Suef \\ University, Egypt \\ ${ }^{2}$ Public Works Department, Cairo University, Egypt
}

\begin{abstract}
Increasing population and expanding urban development in limited spaces involves construction of Narrow Mechanically Stabilized Earth (NMSE) walls having an aspect ratio (ratio of reinforcement length, L, to wall height, $\mathrm{H}$ ) below 0.70 . When constructed in seismically active zones, these walls are subject to seismic ground motions. The purpose of this paper is to present the results of small scale shaking table tests on NMSE walls with rigid facing. A series of reduced scale (1/8 of the prototype model) shaking table tests are performed on a 1dimensional shaking table. The modeled walls have aspect ratio $(\mathrm{L} / \mathrm{H})$ of $0.20,0.30$ and 0.40 . The model is shacked using ramped sinusoidal base accelerations with incrementally increasing displacement amplitude (i.e. actuator stroke) and constant frequencies to generate an equivalent base acceleration ranging from $0.05 \mathrm{~g}$ to $0.70 \mathrm{~g}$ or until failure occurs. Ground motion frequency of $2.5 \mathrm{~Hz}$ is used. The results show that at input accelerations ranging from $0.25 \mathrm{~g}$ to $0.45 \mathrm{~g}$ yielding occurs and the NMSE walls behaves as a rigid body. Subsequently, excessive deformations occur due to the pull out of the top reinforcement layers. An amplification factor of 2.50 times the input ground motion is measured at the surface of the NMSE models. Furthermore, the average design acceleration for the model walls ranges from 1.02 to 1.35 of the input base acceleration.
\end{abstract}

\section{Keywords: (Shaking Table, NMSE Walls, Rigid Face, Reinforcement, Aspect Ratio, Amplification Factor)}

\section{INTRODUCTION}

Recently, there is a need to overcome the geometric constraints of mechanically stabilized earth (MSE) walls at sites having steep terrain or restricted rights-of-way. Thus, narrow mechanically-stabilized earth (NMSE) walls are gaining popularity as a technique to expand the width of embankments and roadways on slopes that are already stable. The definition of NMSE walls here is typically the walls that have an aspect ratio less than 0.70 and constructed in front of an existing stabilized face as stated in Elias et al., (2001) - FHWA and the other common guidelines.

The published database of NMSE walls performance until now includes results from full scale field test (Morrison et al., 2006), centrifuge modeling parametric studies (Woodruff, 2003) and numerical modeling (Yang et al., 2007). However, this database still doesn't provide comprehensive documentations about the behavior of NMSE walls, specifically, when they are constructed in active seismically areas. Thus, a research strategy to quantitatively investigate the seismic behavior of NMSE walls consists of constructing and testing small-scale models using 1-g shaking table. As a first step in this long-term research objective, three 1/8scale model NMSE walls with full-height rigid facings were built up and tested using the uniaxial shake table. The models were subjected to a horizontal stepped-amplitude sinusoidal base acceleration record and tested until producing excessive deformations.

Some of the earliest shaking table modeling to investigate the seismic response of mechanically stabilized earth (MSE) walls reinforced by extensible products (i.e. geosynthetics sheets) 
have been investigated by conducted a series of reduced scale shaking table tests and these models have been reported by Bathurst and Alfaro (1996), Koseki et al. (1998), Matsu et al. (1998), , Sakaguchi et al. (1992), Murata et al. (1994), Bathurst et al. (2002), El-Emam and Bathurst (2004), and Gule and Selek (2014).

Guler and Selek (2014) performed a series of reduced-scale shaking table tests on eight different MSE wall configurations describes the reinforcement length and scaling law behavior on MSE wall with modular block facing. They investigated the effects of change in peak ground acceleration, reinforcement length and spacing, model scale, treatment of the top two facing block layers on the accelerations on a wall face, maximum displacements of the wall face during shaking, permanent displacements, and strains in reinforcement. Maximum accelerations measured on the wall face during shaking increased from bottom to top. Geotextile length and spacing did not affect the maximum accelerations and face displacements when the geotextile length met the minimum requirements of established design procedures. No significant permanent displacements were observed. Decreasing the geotextile length and increasing the geotextile spacing increased the geotextile strains when the geotextile was long enough to provide anchorage beyond the potential failure surface. They, also, deduced the critical failure surface for the tested 8 configurations. These surfaces were assumed at the locations of maximum strains zone generated in geotextile reinforcement.

All previous shaking table models didn't cover the sites having limited spaces or restricted rights-of-way and subsequently, the seismic behavior of NMSE walls has been ignored in current design guidelines (e.g. Bathurst (NCMA) 1998, Elias et al. (2001) - FHWA and AASHTO 2002). NMSE wall defined as wall of aspect ratio (ratio of reinforcement length, L, to wall height, $\mathrm{H})<0.7$ and accordingly the seismic response of these walls are needed to be investigated

\section{SHAKING TABLE AND REINFORCED SOIL MODEL WALL}

\subsection{Shaking table}

The shaking table at Cairo University has one horizontal degree of freedom (I.e. shaking is simulated in one horizontal direction). The table steel platform measures $1.5 \mathrm{~m}$ by $1.5 \mathrm{~m}$, driven by servo-hydraulic actuator. The table maximum payload capacity is 2 tons at frequencies up to $50 \mathrm{~Hz}$ and peak base acceleration amplitude up to $\pm 1 \mathrm{~g}$. The models are confined within a rigid steel square box of dimensions $1.1 \mathrm{~m}$ wide/length by $1.0 \mathrm{~m}$ height that is bolted to the table. The back of the strong box is used to simulate the stable face. Sand papers are attached to the back of the box as well as the base to create a friction between the existing face and the foundation soil. The side walls of the box are constructed with $8 \mathrm{~mm}$-thick of transparent Plexiglas.

\subsection{Wall configuration and model construction}

Fig. 1 highlights the model wall configuration and summarized in Table 1 . A typical cross section and instrumentation plan is described also, in Fig. 1. The experimental design was selected to focus on the influence of the following parameters on wall response during base shaking:

1. Input motion predominant frequency,

2. Input motion amplitude, and

3. Wall aspect ratio. 


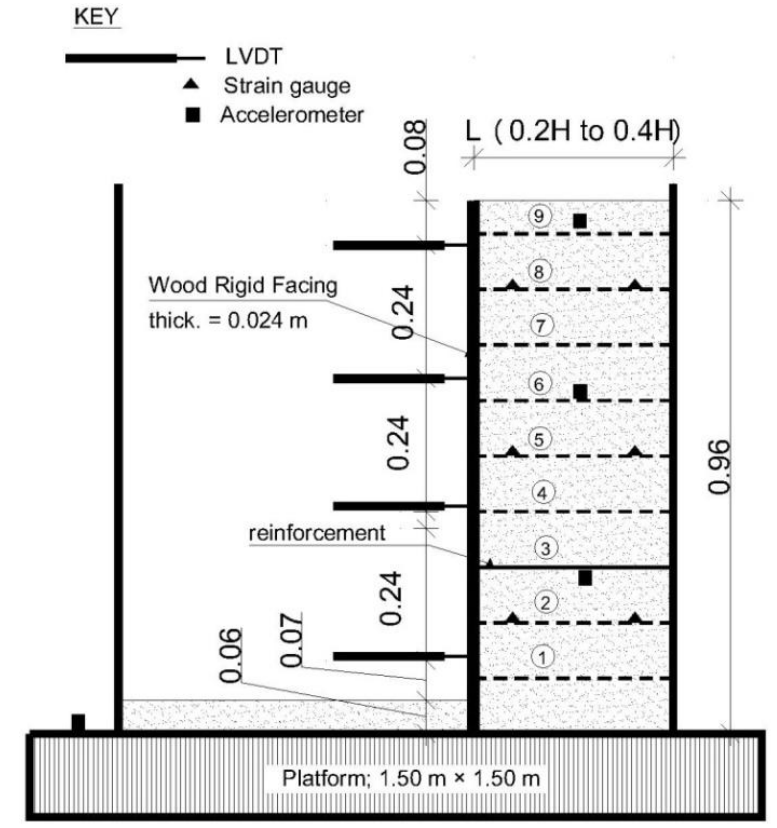

a) Example cross section

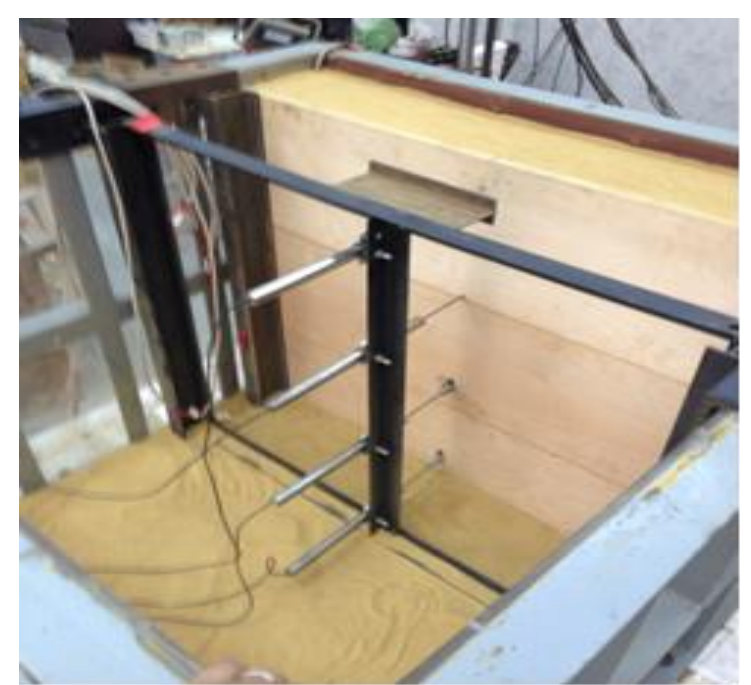

b) 3D view (wall \#3)

Fig. 1: Instrumentation layout and details of reduced scale NMSE wall (all dimensions in m).

b) Table 1: Test configuration and model parameters.

\begin{tabular}{c|c|c|c|c}
\hline \multirow{2}{*}{$\begin{array}{c}\text { Test } \\
\text { number }\end{array}$} & \multicolumn{3}{|c|}{ Reinforcement } & \multirow{2}{*}{$\begin{array}{c}\text { Input motion } \\
\text { frequency }(\mathrm{Hz})\end{array}$} \\
\cline { 2 - 4 } & 0.40 & $\begin{array}{c}\text { Stiffness } \\
(\mathrm{kN} / \mathrm{m})\end{array}$ & $\begin{array}{c}\text { Vertical spacing } \\
(\mathrm{mm})\end{array}$ & 2.5 \\
\hline 1 & 15 & 100 & 2.5 \\
\hline 2 & 0.30 & 15 & 100 & 2.5 \\
\hline 3 & 0.20 & 15 & 100 & \\
\hline
\end{tabular}

$* \mathrm{~L}=$ length of reinforcement and $\mathrm{H}=$ height of the model wall $=0.96 \mathrm{~m}$ in all tests.

The reinforcement length, $\mathrm{L}$, varied to give $\mathrm{L} / \mathrm{H}=0.2,0.3$ and 0.4 , where $\mathrm{H}$ is the height of the reduced model. The reinforcement vertical spacing, $S_{v}$, was taken $0.10 \mathrm{~m}$ in order to isolate the effect of reinforcement density on the dynamic response of the model walls. Full height rigid facing panel of wood is used. The effect of facing rigidity on seismic NMSE wall response will be performed and given on another paper. The facing panel was constructed using 3 panels of counter wood of total thickness $24 \mathrm{~mm}$ as given in Fig. 1.b and interlocking each to gather to perform a full height panel.

For wall construction purposes, bracing system for full height facing panels was used and sand and reinforcement layers in $100 \mathrm{~mm}$ thick lifts were installed. The soil was placed in a loose condition and each lift was compacted to a relative density about $82 \%$ by using a steel hammer of $0.05 \mathrm{kN}$ and falling from $150 \mathrm{~mm}$ Height. Moreover, the reinforcement layers at each lift were placed and bolted to the full height rigid face. Finally, the external bracing system was removed at the end of construction. This condition corresponds to the starting point (static loading condition) prior to shaking.

\subsection{Material}

\subsubsection{Soil}

The backfill material was silica sand obtained from Dahshour district, north of the Nile valley, Giza, Egypt. The specific gravity of the soil is 2.67 and the maximum and minimum void ratios of the sand are 0.77 and 0.59 , respectively. According to the unified soil classification system (USCS), the soil is a uniformly graded sand with about $1 \%$ fines, coefficient of curvature, $\mathrm{C}_{\mathrm{c}}=2.74$ and coefficient of uniformity, $C_{u}=0.91$. In all wall models, the bulk unit weight of the sand was maintained $16.70 \mathrm{kN} / \mathrm{m}^{3}$ 
which give a relative density, $\mathrm{D}_{\mathrm{r}}=82 \%$ and zero moisture content. Tri-axial tests were performed and the material produced a peak friction angle $\phi_{\text {peak }}=41^{\circ}$.

\subsubsection{Reinforcement}

The properties of the geosynthetic material used in the wall model are produced in Table 2. It is a commercially bi-axial knitted polyester (PET) geotextile and coated with polymer of green color which has relatively small tensile strength at $2 \%$ strain. Based upon the scaling law proposed by Iai (1989), the relationship between prototype -scale reinforcement stiffness $\left(\mathrm{J}_{\mathrm{P}}\right)$ and model scale stiffness $\left(\mathrm{J}_{\mathrm{m}}\right)$ can be calculated as $\mathrm{J}_{\mathrm{P}}=\mathrm{J}_{\mathrm{m}} \lambda^{2}$, where $1 / \lambda$ is the model scale and was taken $1 / 8$ in this research.. As stated by Bathurst and Cai (1994), Shinoda and Bathurst (2004) and El-Emam and Bathurst (2004), PET product is used in this study rather than polyolefin material because the axial load-extension properties of PET reinforcement are essentially strain-rate independent.

Table 2: Geogrid reinforcement properties (reduced-scale model).

\begin{tabular}{l|l}
\hline Raw material & Polyester (PET) \\
\hline Coating material & Polymer (color green) \\
\hline Mass/unit area $\left(\mathrm{gm} / \mathrm{m}^{2}\right)$ & 130 \\
\hline Aperture size $(\mathrm{mm})$ & \\
Machine and cross machine direction* & 3.5 \\
\hline Wide-width strip tensile strength $(\mathrm{kN} / \mathrm{m})$ & \\
At $2 \%$ strain $(\mathrm{MD})$ & 2 \\
Ultimate (MD) & 15 \\
\hline
\end{tabular}

\subsection{Instrumentation and base input motion}

Fourteen instruments were used in each model. Four lvdts are mounted at the facing elevation to measure the displacements during base excitation. Each transducer is attached to a rigid vertical steel bracing system that is fixed with the rigid box by c-clamps. Hence, the datum for the recorded displacements is the shaking table platform. Moreover, the local reinforcement strain was measured directly using foil-type strain gauges bonded to the reinforcement longitudinal member. A calibration factor was determined from in-isolation wide-width tensile strip tests to convert the local strains to global strain values and to directly correlate strain gauge readings to average tensile load in the reinforcement. Acceleration response during shaking was measured using accelerometers with a range from $1 \mathrm{~g}$ to $2 \mathrm{~g}$, frequency response were ranged between $1 \mathrm{mv}$ to $5 \mathrm{v}$. three accelerometers were embedded in the soil model in addition to one accelerometer attached to the table platform to measure the input base acceleration as shown in Figure 1.

The horizontal base acceleration is a stepped-amplitude-sinusoidal function as shown in Figure $2 \mathrm{a}$ with a predominant frequency $2.5 \mathrm{~Hz}$ as shown in Fig. 2.b. The amplitude is increased in $0.05 \mathrm{~g}$ increments every $5 \mathrm{sec}$ until excessive deformation occurred. According to Bathurst and Hatami (1998) and Matsu et al. (1998), this simple base excitation record is more aggressive than a typical earthquake record with the same predominant frequency and amplitude. However, this input motion was developed in this form to ensure that all tests were shacked in the same controlled manner and to facilitate quantitative comparison among different tests configurations. 


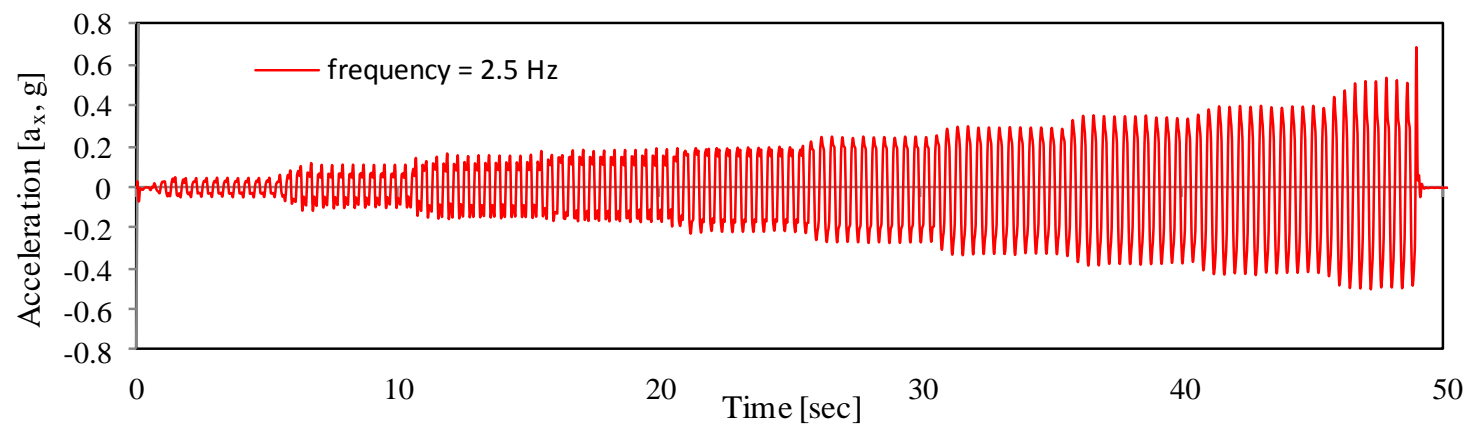

(a) Input base acceleration-time history

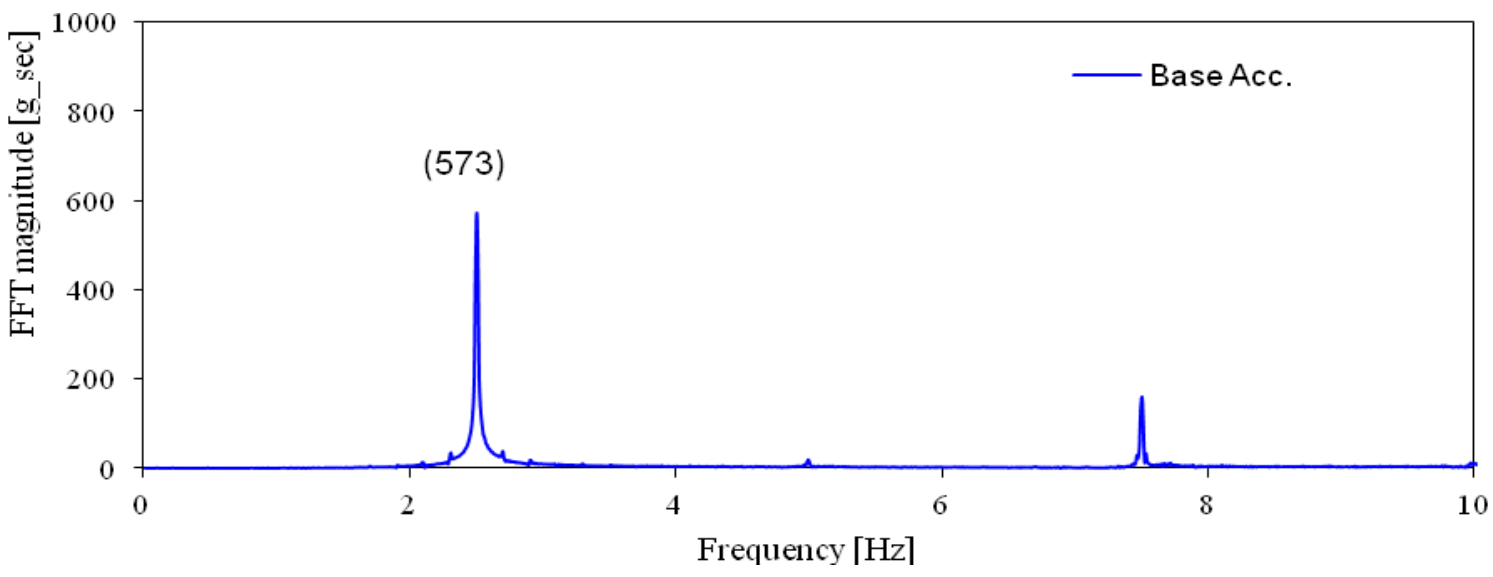

(b) Fast Fourier Transformation (FFTS) for input base accelerations Fig. 2: Measured input base acceleration.

\section{Typical Test Results}

\subsection{General}

This section presents selected test results for test model \# 1. The selected test results show wall displacement behavior with time, input acceleration response through the wall height and results of global strains resulted in reinforcement layers as shown in Fig. 3.

\subsection{Facing displacement}

Results in Fig. 4 produce the effect of ground motion predominant frequencies, amplitude and wall aspect ratio on wall deformations. Total wall displacement at any time was a combination of a recoverable dynamic deformation component and a permanent outward movement of the mean wall position. Similar deformation responses have been reported by Koseki et al. (1998), Matsuo et al. (1998) and El-Emam and Bathurst (2004) for reinforced soil model wall assuming hinged full height rigid facing panel with $\mathrm{L} / \mathrm{H}>0.70$. While this research wall models was assumed to be sliding full height rigid facing panel. The results indicate that the magnitudes of the recoverable and permanent deformations at any times were clearly dependent on the amplitude of the input base acceleration and shaking duration.

It is clear from the results in Fig. 4 that the displacement amplitude and the permanent displacement are small for acceleration amplitudes less than $0.25 \mathrm{~g}$ and $0.37 \mathrm{~g}$. However, the displacement amplitude and permanent deformations of the facing panel increased excessively when the peak base acceleration amplitude increased beyond these threshold acceleration values that reported previously. As stated by Bathurst and Alfaro (1996) and Bathurst et al. (2002) and Cai and Bathurst (1996), a threshold value can be used to identify a critical input base acceleration associated with wall failure in pseudo-static and displacement (sliding block) methods of analysis. 
Although the displacement of wall facing at base acceleration less than the threshold values is small, the wall facing tends to rotate about toe with small toe deformations. This result follows the same behavior as reported by El-Emam and Bathurst. (2004).

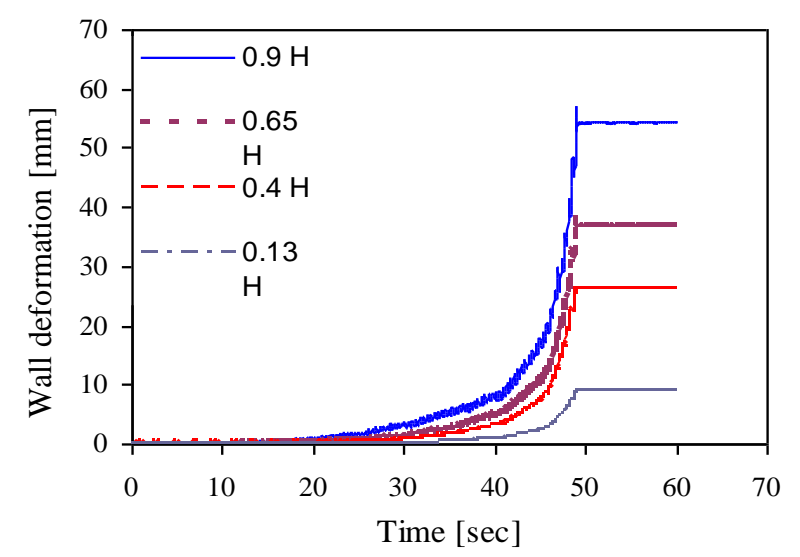

(a) typical displacement-time history

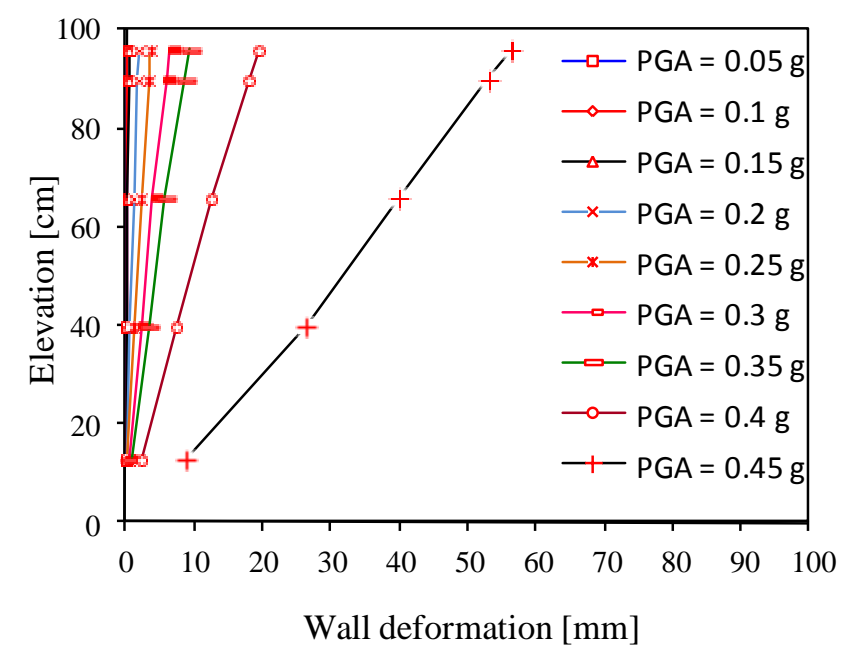

(c) wall rotation versus progression of input peak ground acceleration (PGA)

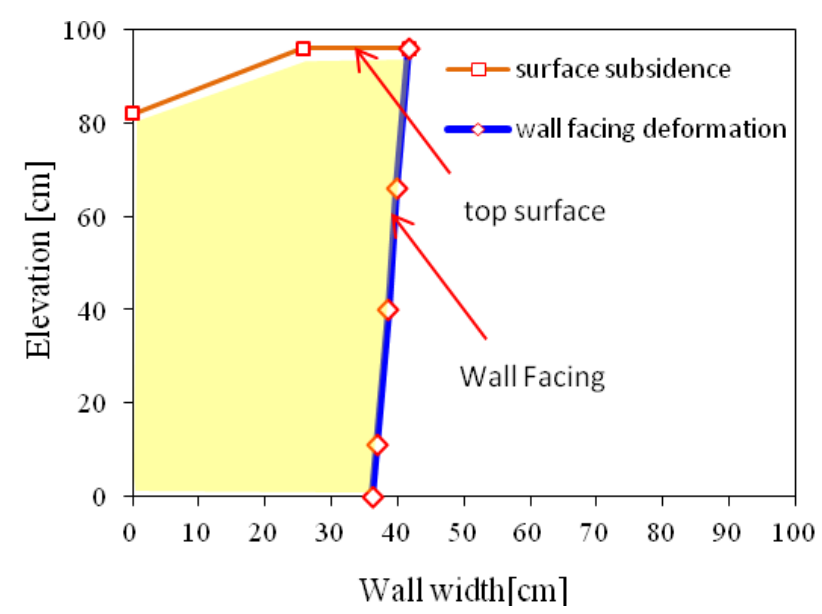

(e) wall deformation and surface subsidence

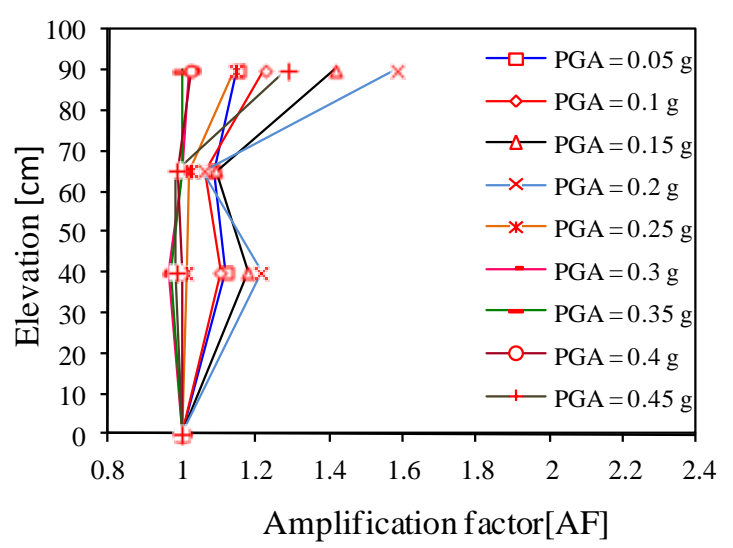

(b) amplification factor profile

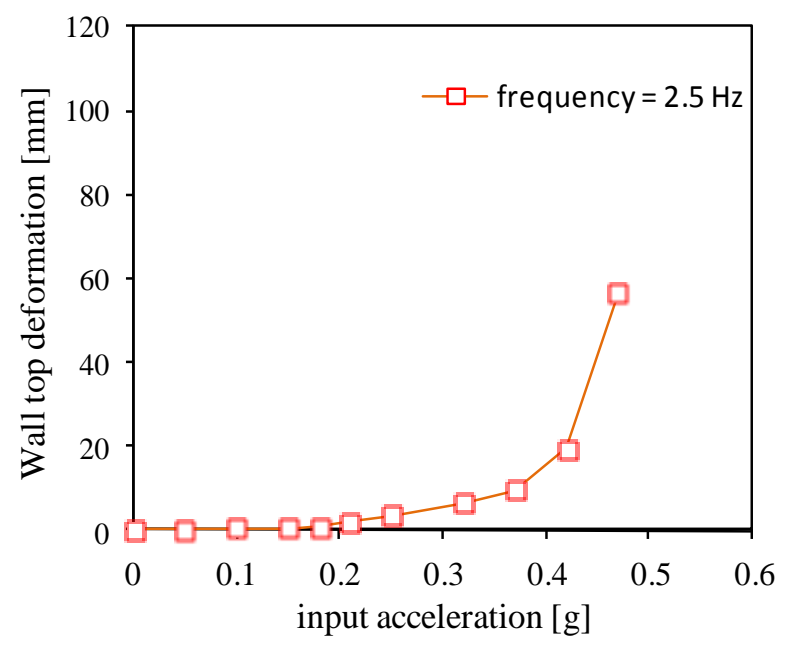

(d) wall deformations versus progression of input peak ground acceleration (PGA)

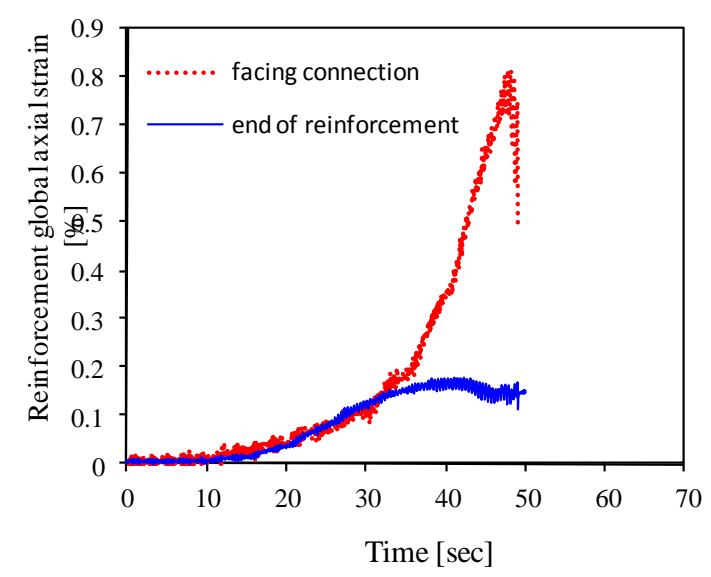

(f) reinforcement global axial strain-time history

Fig. 3: Example model wall \# 2 results of $L / H=0.4$ and frequency $=2.5 \mathrm{~Hz}$. 


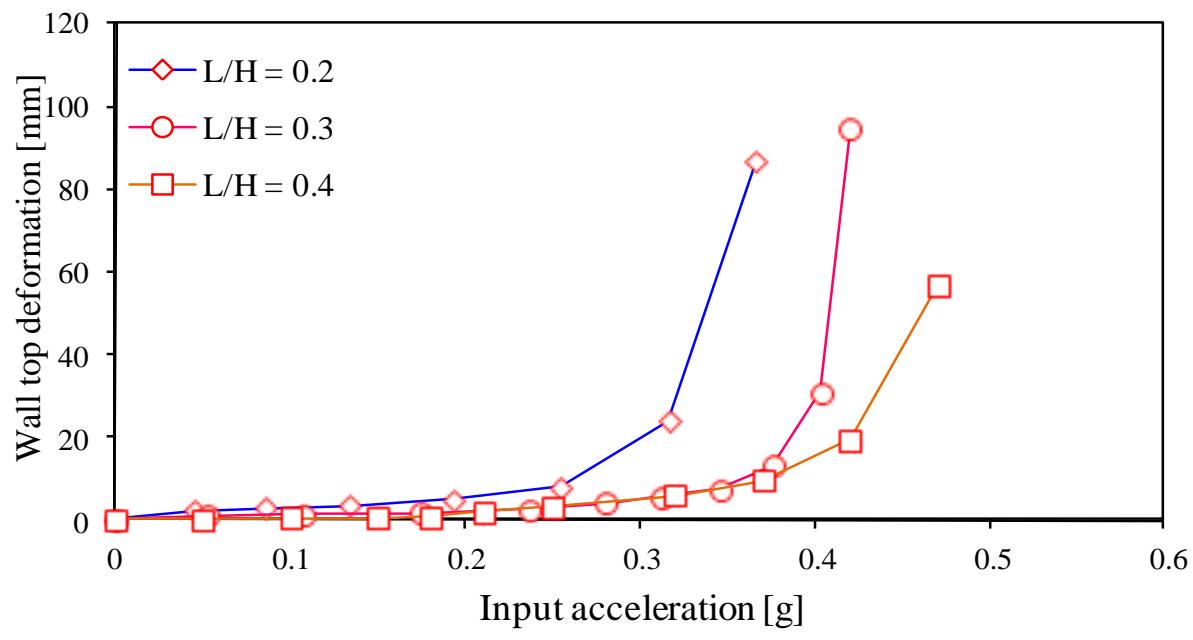

Fig. 4.Top wall displacement versus base acceleration at different aspect ratios

\subsection{Model wall acceleration response}

The input base acceleration and the model wall response acceleration have the same predominant frequency, $2.5 \mathrm{~Hz}$. Acceleration responses were measured at mid-point in the reinforced soil mass at elevations $0.3,0.6$ and $0.9 \mathrm{~m}$, respectively. The results show an amplification factor up to 1.8 at the wall crest. Generally, the amplification factor increased as the input motion acceleration amplitude increased. However for walls have $\mathrm{L} / \mathrm{H}<0.4$ the amplification factors were relatively small (between 1.05 to 1.15 ) beyond input acceleration amplitude of $0.3 \mathrm{~g}$ and increased thereafter up to 1.50. A possible ekplanation is that large deformations that occurred close to the threshold acceleration might haye to lead to reduction in the model wall stiffness. Consequently, the amplification factors increased. While for walls have $\mathrm{L} / \mathrm{H} \geq 0.4$, the response of input acceleration amplification was different. The results show that the amplification factors increase significantly beyond input accelerations of about 0.2 to $0.3 \mathrm{~g}$. Then, model wall offers a slightly amplification factor. These results are similar to the behavior reported by El-Emam and Bathurst (2004) and confirm the decoupling phenomenon stated by Muir wood et al. (2002). This phenomenon proved that the shorter walls (e.g. $\mathrm{H}<3 \mathrm{~m}$ ) resulted in higher amplification factor at low to moderate input acceleration amplitudes and reduced thereafter. This was attributed to the decoupling of backfill at strong ground motions reduce its bearing capacity to transmit the shear stresses to higher elevations which would otherwise contribute to acceleration amplification up to the height of the backfill.

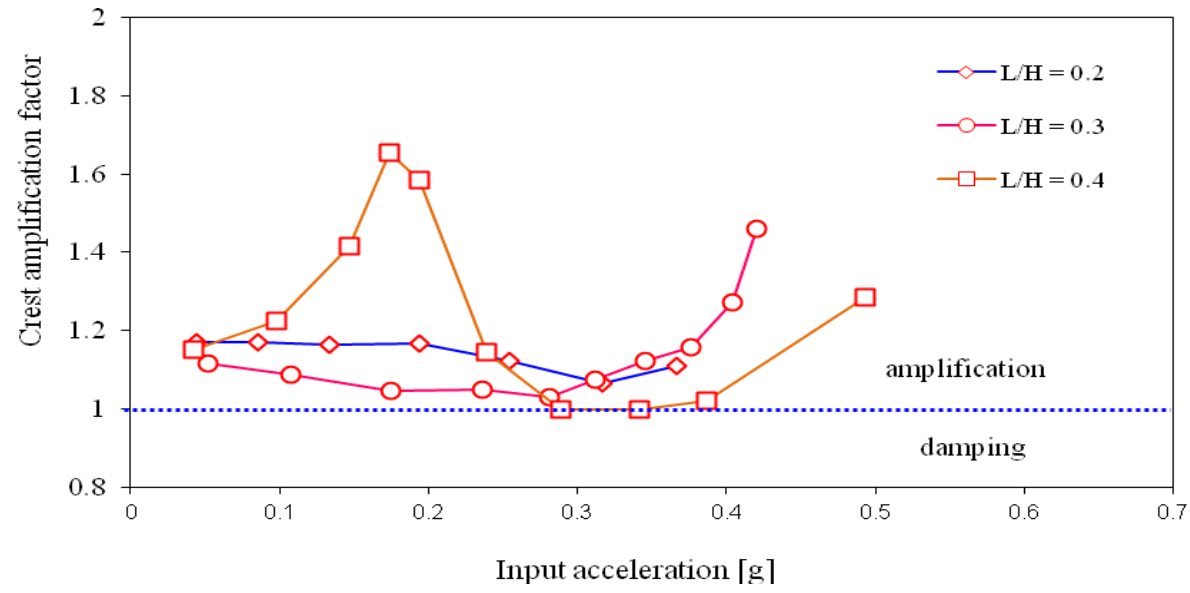

Fig. 5. Crest amplification factor versus base acceleration at different aspect ratios
4. CONC LUSIO NS

This paper is a part of $\mathrm{a}$ comprehensive research which going on the seismic behavior of 
NMSE walls. The paper presents the results of series of reduced scale shaking table tests that describe the seismic response of full-height rigid facing NMSE walls considering the ground motion characteristics and the wall configuration. The following conclusions are obtained:

i. The modeled NMSE walls are stable at input base acceleration ranges from $0.25 \mathrm{~g}$ to 0.37 g. Thereafter, excessive deformations for the wall facing panel occur.

ii. The results show, also, that the wall rotation accompanies by a significant surface subsidence which creates a trench shape between the modeled walls and the stabilized face; tank boundary.

iii. It is obvious from the results that decreasing the wall aspect ratio produces lower yield accelerations.

iv. An amplification factor up to 1.8 is measured at the surface of the modeled walls. For NMSE walls of $\mathrm{L} / \mathrm{H}=0.4$, the input acceleration response follows the decoupling phenomenon of Muir Wood (2002). The phenomenon shows that the shorter walls (e.g. H < $3 \mathrm{~m}$ ) offers higher amplification factor at small to moderate ground motions. While for strong motions the soil-reinforcement system has been decoupled and its bearing capacity reduced. Consequently, NMSE will not be able to transmit shear stresses to higher elevations. However, for NMSE walls of $\mathrm{L} / \mathrm{H}<0.4$, the amplification factor increases with increasing the input acceleration amplitude due to the reduction in the system stiffness. The stiffness reduction can be attributed to the reduction of soil shear modulus in the regions of large deformations.

\section{REFERENCES}

1. AASHTO, 2002. Standard Specifications for Highway Bridges, 17th ed. American Association of State Highway and Transportation Officials, Washington, DC.

2. Bathurst, R. J. \& Alfaro, M.C. 1996. Review of seismic design, analysis and performance of geosynthetic reinforced walls, slopes and embankments, Keynote paper. In: Ochiai, H., Yasufuku, N., Omine, K. (Eds.), Proceeding of the International Symposium on Earth Reinforcement. Fukuoka, Kyushu, Japan, 12-14 November 1996. vol. 2. Balkema, Rotterdam, pp. 887-918.

3. Bathurst, R. J. \& Cai, Z. 1994. In-isolation cyclic load-extension behaviour of two geogrids. Geosynthetics International, 1, Vol. 1, pp.3-17.

4. Bathurst, R. J. \& Hatami, K. 1998. Seismic response analysis of a geosynthetic-reinforced soil retaining wall. Geosynthetics International, 5, Vol. 1-2, pp. 127-166.

5. Bathurst, R. J. 1998. NCMA Segmental Retaining Wall Seismic Design ProcedureSupplement to Design Manual for Segmental Retaining Walls. National Concrete Masonry Association, Herndon, VA, USA, 187p.

6. Bathurst, R. J., Cai, Z. and Pelletier, M. J. 1996. Seismic design and performance of geosynthetic reinforced s mental retaining walls. Proceedings of the 10th Annual Symposium of the Vancouver Geotechnical Society, Vancouver, BC, Canada, 26 pp.

7. Bathurst, R. J., Hatami, K. and Alfaro, M.C., 2002. Geosynthetic-reinforced soil walls and slopes-seismic aspects. In: Shukla, S.K. (Ed.), Geosynthetics and their Applications. Thomas Telford Ltd., London, UK, pp. 327-392.

8. Cai, Z. \& Bathurst, R. J. 1996. Deterministic sliding block methods for estimating seismic displacements of earth structures. Soil Dynamics and Earthquake Engineering, 15, Vol. 4, pp. 255-268.

9. El-Emam, M. \& Bathurst, R. J. 2004. Experimental design, instrumentation and interpretation of reinforced soil wall response using a shaking table. International Journal of Physical Modelling in Geotechnics, 4, Vol. 4, pp. 13-32.

10. Elias, V., Christopher, B. R. and Berg, R.R., 2001. Mechanically stabilized earth walls and reinforced soil slopes-design and construction guidelines. FHWA-NHI-00-043, Federal Highway administration, Washington, D.C., U.S.A., 418 p.

11. Guler, E. and Selek, O. 2014. Reduced-Scale Shaking Table Tests on GeosyntheticReinforced Soil Walls with Modular Facing. J. Geotech. Geoenviron. Eng., Vol. 140, pp. 04014015.

12. Iai, S. 1989. Similitude for shaking table tests on soil-structure-fluid models in 1-g gravitational field. Soils and Foundations, Vol. 29, No. 1, pp. 105-118. 
13. Koseki, J., Munaf, Y., Tatsuoka, F., Tateyama, M., Kojima, K and Sato, T. 1998. Shaking and tilt table tests of geosynthetic-reinforced soil and conventional-type retaining walls. Geosynthetics International, Vol. 5, pp. 73-96.

14. Matsuo, O., Tsutsumi, T., Yokoyama, K. and Saito, Y. 1998. Shaking table tests and analysis of geosynthetic-reinforced soil retaining walls. Geosynthetics International, Vol. 5, pp. 97-126.

15. Morrison, K., Harrison, F., Collin, J., Dodds, A. and Arndt, B. 2006. Shored Mechanically Stabilized Earth (SMSE) Wall Systems. FHWA-CFL/TD-06-001. 212 pg.

16. Muir Wood, D., Crewe, A. and Taylor, C. 2002. Shaking table testing of geotechnical models. International Journal of Physical Modelling in Geotechnics, vol. 2, pp. 1-13.

17. Murata, O., Tateyama, M. and Tatsuoka, F. 1994. Shaking table tests on a large geosynthetic-reinforced soil retaining wall model. In Recent Case Histories of Permanent Geosynthetic-Reinforced Soil Walls (eds F. Tatsuoka and D. Leshchinsky), pp. 287-294. Rotterdam: Balkema.

18. Sakaguchi, M., Muramatsu, M. and Nagura, K. 1992. A discussion on reinforced embankment structures having high earthquake resistance. In: Ochiai, H., Hayashi, S., Otani, J. (Eds.), Proceeding of International Symposium on Earth Reinforcement Practice, ISKyushu'92, Fukuoka, Japan. Balkema, Rotterdam, pp. 287-292.

19. Shinoda, M. \& Bathurst, R. J. 2004. Lateral and axial deformation of PP, HDPE and PET geogrids under tensile load. Geotextiles and Geomembranes, Vol. 22, pp. 205-222.

20. Woodruff, R. 2003. Centrifuge modelling for MSE-shoring composite walls. M.S. Thesis. University of Colorado at Boulder.

21. Yang, K.-H., Zornberg, J.G., Wright, S.G., and Kniss, K.T. 2007. Numerical modelling of narrow MSE walls with extensible reinforcements. FHWA/TX-08/0-5506-2. 